\title{
Ampakines Attenuate Staurosporine-induced Cell Death in Primary Cortical Neurons: Implications in the 'Chemo-Brain' Phenomenon
}

\author{
DANIEL P. RADIN, GARY A. ROGERS*, KIMBERLEY E. HEWITT, RICHARD PURCELL and ARNOLD LIPPA
}

\author{
RespireRx Pharmaceuticals, Inc., Glen Rock, NJ, U.S.A.
}

\begin{abstract}
Background/Aim: Mounting evidence suggests that trophic cell signaling can be mediated by alpha-amino-3hydroxy-5-methyl-4-isoxazolepropionic acid receptor (AMPAR) activation. It has been demonstrated that exogenous application of brain-derived neurotrophic factor (BDNF) is highly neuroprotective in vitro against neurotoxic insults such as standard chemotherapies. Materials and Methods: Because positive allosteric modulation of AMPARs with ampakines can increase both BDNF $m R N A$ and protein in vitro and in vivo, we examined whether application of the ampakines CX614 and CX729 promoted neuroprotection against staurosporineinduced cell death in rat primary cortical neurons using propidium iodide to stain for dead cells. Results: A transient 2-h pretreatment with CX614 or CX729 performed 24 h prior to staurosporine produced significant, time-dependent neuroprotection that was resistant to the AMPAR antagonists $N B Q X$ or GYKI 52466, suggesting that this effect may be independent of ion flow. Furthermore, the pretreatment time requirements of CX729 matched the time course for increased BDNF expression previously reported to occur in hippocampal slices, suggesting that increased neurotrophin expression might be associated with the neuroprotective effects conferred by ampakines. Conclusion: Our data demonstrate that ampakines may be able to perturb neuronal toxicity and peripheral neuropathy of front-line chemotherapies.
\end{abstract}

It is now becoming more widely accepted that ionotropic alpha-amino-3-hydroxy-5-methyl-4-isoxazolepropionic acid

*Current address: Medical School of the Americas, Nevis, West Indies.

Correspondence to: Daniel Radin, RespireRx Pharmaceuticals Inc., 126 Valley Road, Glen Rock, NJ 07452, U.S.A. Tel: +1 2016790671, Fax: +1 2014930887, e-mail: dradin@respirerx.com

Key Words: Ampakine, cell death, neuroprotection, neurotrophin, staurosporine. receptor receptors (AMPARs) act as more than ligand-gated sodium channels. AMPARs are also ligand-gated calcium channels with Gi-protein coupling (1). This discovery was followed by the determination that AMPAR signaled to the mitogen-activated protein kinase (MAPK) in a pertussis toxin-sensitive manner and that the downstream signaling cascade resulted in increased brain-derived neurotrophic factor (BDNF) expression (2). BDNF is a neurotrophin that exerts its effects through the tropomyosin-related kinase $\mathrm{B}$ (TrKB) receptor activation, and is highly neuroprotective against excitotoxicity when exogenously applied in vivo and in vitro (3-5).

Ampakines act as positive allosteric modulators of AMPARs and have been reported to increase both mRNA and protein levels of BDNF in hippocampal neurons in vitro (6) and mRNA levels in vivo (7, unpublished data), demonstrating that these drugs are also capable of modulating this neurotrophic signaling pathway, presumably by potentiating the actions of endogenous glutamate. While excessive glutamate release has been proposed to underlie neuronal excitotoxicity (8), the trophic signaling pathways associated with AMPAR activity may explain how, in other circumstances, the activation of glutamate receptors can act as a survival signal. Bambrick et $a l$. showed that glutamate induced neuronal survival in cultured murine hippocampal cells, and blockade of AMPAR/kainate receptors increased neuronal death (9). Similarly, McKinney et al. demonstrated that AMPAR activation spared dendritic spines from degeneration induced by deafferentation or botulinum toxin (10).

A significant subset of patients with cancer experience either cognitive impairments (11), peripheral neuropathy (12) with/without changes in white matter volume in the brain (11) as they progress through chemotherapy treatments collectively termed 'chemo-brain'. Currently, no treatment exists to prevent these varying degrees of neurological complications and sometimes chemotherapy needs to be stopped due to neurological side-effects.

For these reasons, the present study examined whether positive AMPAR modulation by the ampakines CX614 and 
CX729 promoted survival in primary cortical neurons induced to undergo cell death by exposure to staurosporine and whether such actions of the ampakines required the activation of cation channels.

\section{Materials and Methods}

All animal procedures were conducted in accordance with the federal register's guides on acceptable principles of use of vertebrate animals in research testing (13) with protocols approved 1R4NS38404] by the Institutional Animal Care and Use Committee of the University of California at Irvine (Irvine, CA, USA). Efforts were made to minimize animal suffering and the numbers of rats used in the work described.

Reagents. Dulbecco's phosphate-buffered saline, Eagle's minimum essential medium (MEM), 5-fluoro-'2-deoxyuridine, poly-L-lysine, propidium iodide, trypan blue, uridine and $\mathrm{KCl}$ were purchased from Sigma Chemical Co. (St. Louis, MO, USA). Heat-inactivated fetal bovine serum (FBS) and heat-inactivated horse serum (HS) were from Hyclone Laboratories (Logan, UT, USA). L-Glutamine was purchased from GIBCO Laboratories (Grand Island, NY, USA). Staurosporine was from Calbiochem (La Jolla, CA, USA). The competitive AMPAR antagonist NBQX was obtained from Tocris Cookson (Langford, Bristol, UK) and the non-competitive AMPAR antagonist GYKI52466 were purchased from RBI (Natick, MA, USA). CX614 (2H,3H,6aH-pyrrolidino[2', 1',-3',2']1,3-oxazino [6',5'-5,4]benzo[e]1,4-dioxan-10-one), CX729 (pyrrolo[2,1b]pyrrolo[2', 1':2,3][1,3] oxazino[6,5-g][1,3]benzoxazine-6,13-dione, 1,2,3,3a,8,9,10,10a-octahydro-(3aR,10aR)) and CX743 (pyrrolo[2,1b]pyrrolo[2',1':2,3][1,3] oxazino[6,5-g][1,3]benzoxazine-6,13dione, 1,2,3,3a,8,9,10,10a-octahydro-(3aS,10aS) were synthesized at RespireRx Pharmaceuticals (Glen Rock, NJ, USA).

Primary neuronal cultures. Cultures of E18 rat cortical neurons were prepared as previously described (14). Briefly, timedpregnant Sprague-Dawley rats (Harlan-Sprague Dawley;San Diego, CA, USA) were anesthetized using halothane anesthesia and killed by cervical dislocation following 18 days of gestation. Fetuses were removed and the cortical region of their brains dissected. Dispersion of cortical neurons was accomplished using a $10 \mathrm{ml}$ pipette, and the cells centrifuged at $250 \times \mathrm{g}$ for $5 \mathrm{~min}$ at $4^{\circ} \mathrm{C}$. Cells were plated on poly-L-lysine coated, 35-mm-diameter tissue culture dishes at $10^{5}$ cells $/ \mathrm{cm}^{2}$ in plating medium consisting of $80 \%$ MEM, $10 \% \mathrm{FBS}, 10 \% \mathrm{HS}$, and $2 \mathrm{mM}$ L-glutamine, and incubated at $37^{\circ} \mathrm{C}$ in $5 \% \mathrm{CO}_{2}$ and $95 \%$ air. Cultures were treated with $15 \mu \mathrm{g} / \mathrm{ml} 5$-fluoro-2'-deoxyuridine and $35 \mu \mathrm{g} / \mathrm{ml}$ uridine on day 4 of culture to minimize glial cell growth. The cultures were supplemented with growth medium consisting of $90 \%$ MEM and $10 \%$ HS 1 week after plating. Experiments were performed on cells after 16-20 days in culture. Murine embryonic neurons were previously shown to express predominantly flip variants of AMPAR (15).

Culture treatments. One-half of the medium from cortical cultures was removed and saved. Cells were pre-treated with $50 \mu \mathrm{M} \mathrm{CX614}$

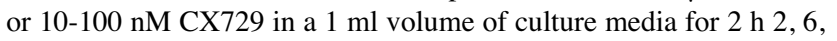
or $24 \mathrm{~h}$ prior to, concomitantly with or $2 \mathrm{~h}$ after initiating staurosporine treatment. Following ampakine exposure, the drugcontaining culture media were removed, the cells were washed with
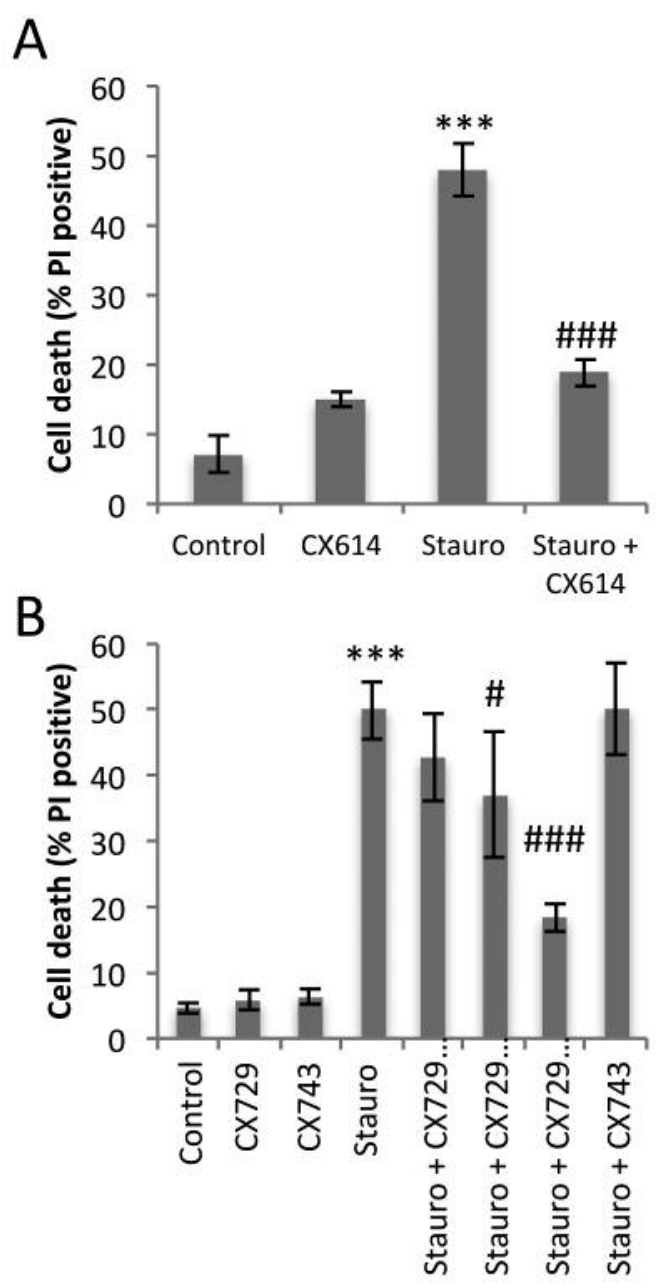

Figure 1. Ampakines CX614 and CX729 attenuate staurosporine-induced cell death. Cells were transiently pre-treated with CX614 $(50 \mu M)(A)$ or CX729/CX743 (100 nM) (B) for $2 \mathrm{~h}$, and subsequently exposed to staurosporine (Stauro, $1 \mu M$ ) 24 h later. Cell viability determinations were made using propidium iodide (PI) exclusion $24 \mathrm{~h}$ after staurosporine was introduced to the culture media. ANOVA gave $p<0.01$, suggesting a significant dose-dependent response to CX729. Bars represent the means $\pm S E M$ from three to six experiments performed in triplicate. Significantly different at $* * * p<0.001$ compared to control;

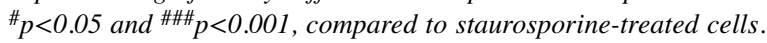

a controlled salt solution, which consisted of $120 \mathrm{mM} \mathrm{NaCl}, 5.4 \mathrm{mM}$ $\mathrm{KCl}, 0.8 \mathrm{mM} \mathrm{MgCl} 2,1.8 \mathrm{mM} \mathrm{CaCl}_{2}$, and $15 \mathrm{mM}$ glucose, buffered with $25 \mathrm{mM}$ Tris, $\mathrm{pH} 7.4$, and the saved conditioned medium was returned to the plates. Staurosporine $(1 \mu \mathrm{M})$ was added to the remaining culture media post-ampakine administration.

Twenty-four hours after the addition of staurosporine, cell viability was assessed by propidium iodide (PI) exclusion. Live cells were counted as phase-bright cells under phase-contrast microscopy, and the number of PI-labeled nuclei (dead cells) under fluorescence microscopy. Cell death was expressed as the percentage of PIlabeled neurons [i.e. PI-labeled/(phase bright+PI-labeled neurons)]. 


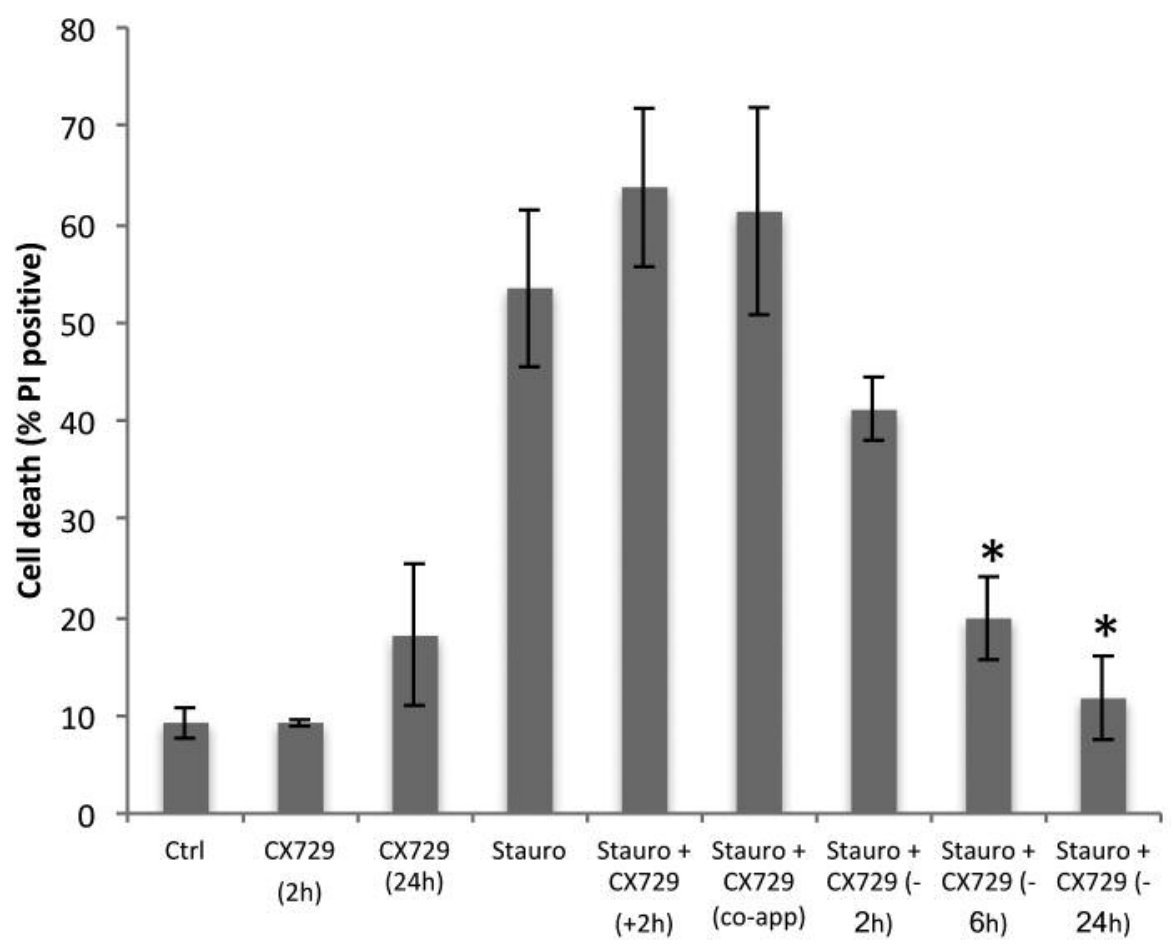

Figure 2. Pre-treatment with CX729 was necessary to invoke neuroprotection. Cells were treated with 100 nM CX729 for 2 h, with staurosporine (Stauro, $1 \mu \mathrm{M}$ ) added at the indicated times. Cell viability determinations were made using propidium iodide (PI) exclusion. Neuroprotective efficacy required a delay, since increasing the time between ampakine administration and staurosporine conferred greater neuroprotection. Concomitant or subsequent application of the ampakine was ineffective. ANOVA gave $p<0.01$, suggesting a significant time-dependent response. Bars represent the means $\pm S E M$ from two independent experiments performed in triplicate. $*$ Significantly different at $p<0.05$, compared to staurosporine-treated cells.

Data analysis. Data were analyzed using Microsoft 2011 (Microsoft, Redmond, WA, USA). One-way analysis of variance and $t$-tests were used to analyze data. All assays were performed in triplicate at least twice $(n=2-6)$.

\section{Results}

Incubation with $50 \mu \mathrm{M}$ CX614 or $100 \mathrm{nM}$ CX729 (Figure 1) produced no significant $(p>0.05, t$-test) effects on cell viability when administered alone. Protracted exposure of primary cortical neurons to $1 \mu \mathrm{M}$ staurosporine caused death in approximately $50 \%$ of the cells when cell viability was assessed $24 \mathrm{~h}$ after its addition (Figure 1). However, when neurons were transiently pre-exposed to $50 \mu \mathrm{M}$ CX614 (Figure 1a) or $100 \mathrm{nM} \mathrm{CX729} \mathrm{(Figure} \mathrm{1b)} \mathrm{for} 2 \mathrm{~h}, 24 \mathrm{~h}$ prior to the addition of staurosporine $(1 \mu \mathrm{M})$, cell death was significantly attenuated $(p<0.001, t$-test $)$. CX743, the physiologically inactive enantiomer of CX729, had no effect, suggesting that positive allosteric modulation of AMPAR was responsible for the observed neuroprotective effects.

The ability of CX729 to attenuate staurosporine-induced cell death was also concentration dependent ( $p<0.01$, ANOVA). The minimal effective dose in these experiments was $30 \mathrm{nM}$, a dose comparable to that required to enhance field excitatory post-synaptic potentials recordings in hippocampal slices (unpublished observations) with maximal protection of $80-95 \%$ achieved with $100 \mathrm{nM}$ (Figures 1B and 2).

The timing requirements for ampakine treatment were also examined using CX729, by varying the amount of time between the washout of the ampakine and the initiation of the staurosporine application. CX729 was applied for $2 \mathrm{~h}$ at 2, 6 and $24 \mathrm{~h}$ prior to staurosporine application. In addition, the compound was applied simultaneously with staurosporine (time 0 ) or $2 \mathrm{~h}$ after the addition of staurosporine and remained in the incubation medium without washout. Results showed that neuroprotection was conferred across all time intervals with significance ( $p<0.05, t$-test; $p<0.01$, ANOVA) as early as $6 \mathrm{~h}$ post-ampakine application, with maximal effects occurring after a 24-h delay between ampakine pretreatment and staurosporine application (Figure 2). No protection was seen when the compound was co-applied, or applied after staurosporine introduction.

Application of the competitive AMPAR antagonist NBQX $(10 \mu \mathrm{M})$ or the non-competitive AMPAR antagonist GYKI $52466(30 \mu \mathrm{M})$ did not produce any cytotoxic effects when 


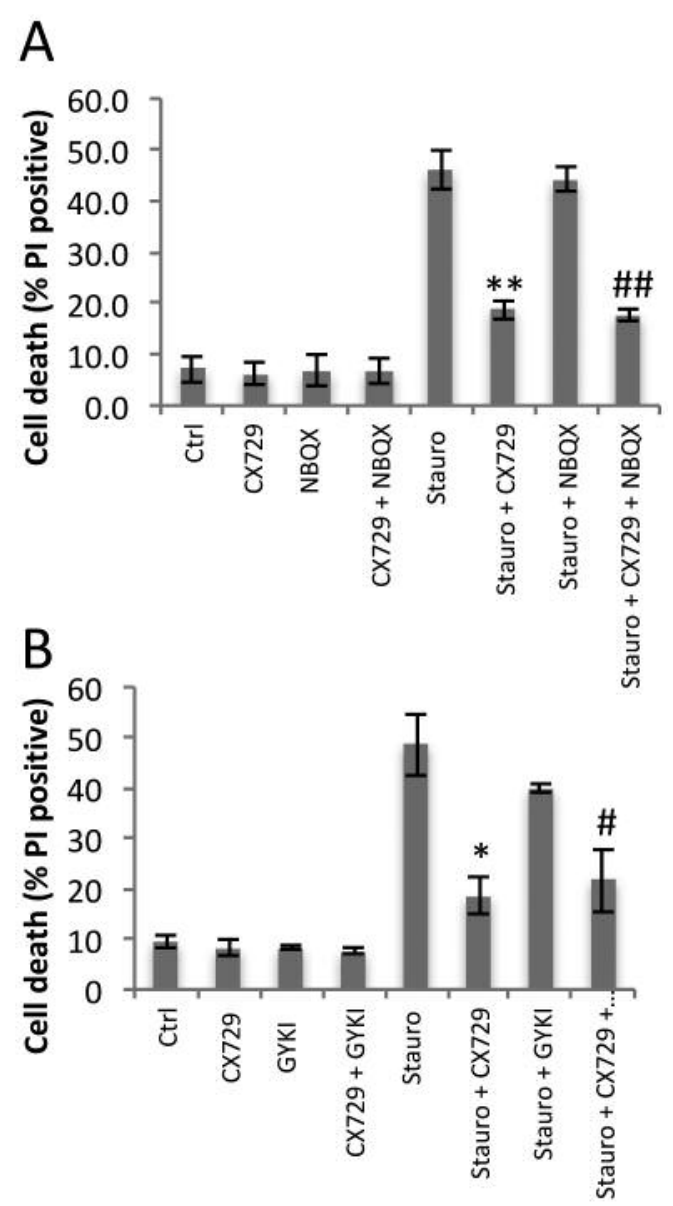

Figure 3. Alpha-amino-3-hydroxy-5-methyl-4-isoxazolepropionic acid receptor (AMPAR) blockage did not prevent neuroprotection by CX729. Competitive antagonist NBQX $(10 \mu M)(A)$ or non-competitive antagonist GYKI $52466(30 \mu M)(B)$ were co-applied with CX729 (100 nM) for $2 \mathrm{~h}$. Cells were washed twice for $5 \mathrm{~min}$ in saline, returned to conditioned media, with staurosporine (Stauro, $1 \mu \mathrm{M}$ ) added $24 \mathrm{~h}$ later. Assessment of cell viability $24 \mathrm{~h}$ after staurosporine application using propidium iodide (PI) exclusion revealed that neither NBQX nor GYKI 52466 prevented CX729 from exacting its neuroprotective effect. Bars represent the means $\pm S E M$ from two to three independent experiments performed in triplicate. Significantly different at $* p<0.05$ and $* * p<0.01$ compared to staurosporine-treated cells; ${ }^{\#} p<0.05$ and ${ }^{\# \#} p<0.01$ compared to cells treated with staurosporine and respective AMPAR blocker.

administered alone; nor did they alter the cytotoxic effects of staurosporine or the neuroprotective effects produced by CX729 (Figure 3).

\section{Discussion}

The present results demonstrate the ability of ampakine administration to produce a time- and dose-dependent increase in the survival of primary cultures of rat cortical neurons when these cells were treated with staurosporine. These ampakine effects were enantiomer-specific and not affected by NBQX or GKYI-52466, competitive and non-competitive antagonists of AMPA receptor channel activity, respectively. These same ampakines have been observed to produce a facilitation of fEPSP in rat hippocampus, an effect antagonized by NBQX (unpublished observations), suggesting that they do act on AMPARs. The present results raise the possibility that these protective properties of ampakine might act independently of what is considered the classic ionotropic AMPAR. In this regard, it is interesting to note that there has been a report of increased BDNF expression via AMPAR signaling that was independent of ion flow (2).

A minimal pretreatment time of at least $6 \mathrm{~h}$ proved necessary for significant protective effects. This timing requirement suggests the possibility that new protein synthesis might be a necessary feature of ampakine-mediated neuroprotection and that positive allosteric modulation of AMPARs by ampakines might induce signaling cascades that promote neuroprotection. Consistent with this idea, the timing requirements matched those necessary for neurotrophin induction in hippocampal slice (6).

Given that ampakines can cross the blood-brain barrier, treating patients with a bolus of either CX614 or CX729 1 day prior to chemotherapy rounds may spare them from certain neurological side-effects associated with standard DNAdamaging agents or other front-line chemotherapies. It is also fortuitous that CX614 has been shown to elicit oncolytic effects in multiple cancer types (16); an agent that can inhibit cancer cell proliferation and protect non-transformed cells is sorely needed in the clinic. Furthermore, there are accumulating data to show that increased BDNF in the hypothalamus produces an immune-stimulating and subsequent oncolytic effect in vivo (17, 18). Moreover, patients with higher serum BDNF levels experience longer survival times (19), demonstrating that upregulation of BDNF in key brain regions may not only have neuroprotective effects, but also key oncolytic effects (20). With these ideas in mind, our work demonstrates that AMPAR activation by ampakines may not only serve a multi-faceted role in reducing neuronal toxicity and negating the 'chemo-brain' phenomenon associated with common chemotherapies, but may also stimulate the patient's immune system to attack tumors.

\section{References}

1 Wang Y, Small DL, Stanimirovic DB, Morley P and Durkin JP: AMPA receptor-mediated regulation of the Gi-protein in cortical neurons. Nature 389: 502-504, 1997.

2 Hayashi T, Umemori $\mathrm{H}$, Mishina $\mathrm{M}$ and Yamamoto T: The AMPA receptor interacts with and signals through the protein tyrosine kinase Lyn. Nature 397: 72-76, 1999.

3 Tremblay R, Hewitt K, Lesiuk H, Mealing G, Morley P and Durkin JP: Evidence that brain-derived neurotrophic factor neuroprotection is linked to its ability to reverse the NMDAinduced inactivation of protein kinase $\mathrm{C}$ in cortical neurons. $\mathrm{J}$ Neurochem 72: 102-111, 1999. 
4 Ferrer I, Ballabriga J, Marti E, Perez E, Alberch J and Arenas E: BDNF up-regulates TrkB protein and prevents the death of CA1 neurons following transient forebrain ischemia. Brain Pathol 8: 253-261, 1998.

5 Cheng Y, Gidday JM, Yan Q, Shah AR and Holtzman DM: Marked age-dependent neuroprotection by brain-derived neurotrophic factor against neonatal hypoxic-ischemic brain injury. Ann Neurol 41: 521-529, 1997.

6 Lauterborn JC, Lynch G, Vanderklish P, Arai A and Gall CM: Positive modulation of AMPA receptors increases neurotrophin expression by hippocampal and cortical neurons. J Neurosci 20: 8-21, 2000.

7 Mackowiak M, O’Neill MJ, Hicks CA, Bleakman D and Skolnick P: An AMPA receptor potentiators modulates hippocampal expression of BDNF: An in vivo study. Neuropharmacology 43(1): 1-10, 2002.

8 Brorson J, Manzolillo P, Gibbons S and Miller R: AMPA receptor desensitization predicts the selective vulnerability of cerebellar purkinje cells to excitotoxicity. J Neurosci 15(6): 4515-4524, 1995.

9 Bambrick LL, Yarowsky PJ and Krueger BK: Glutamate as a hippocampal neuron survival factor: an inherited defect in the trisomy 16 mouse. Proc Natl Acad Sci USA 92: 9692-9696, 1995.

10 McKinney RA, Capogna M, Durr R, Gahwiler BH and Thompson SM: Miniature synaptic events maintain dendritic spines via AMPA receptor activation. Nat Neurosci 2: 44-49, 1999.

11 Silverman DS, Dy CJ, Castellon SA, LaiJ, Pio BS, Abraham L, Waddell K, Peterson L, Phelps ME and Ganz PA: Altered frontocortical, cerebellar and basal ganglia activity in adjuvanttreated breast cancer survivors 5-10 years after chemotherapy. Breast Cancer Res Treat 103(3): 303-311, 2007.

12 Kleckner IR, Kamen C, Gewandter JS, Mohile NA, Heckler CE, Culakova E, Fung C, Janelsins MC, Asare M, Lin PJ, Reddy PS, Giguere J, Berenberg J, Kesler SR and Mustian KM: Effects of exercise during chemotherapy on chemotherapy-induced peripheral neuropathy: a multicenter, randomized control trial. Support Care Cancer 26(4): 1019-1028, 2018
13 Federal Register. (1985). Principles for the Utilization and Care of Vertebrate Animals Used in Testing, Research, and Training. 50(97).

14 Hewitt KE, Lesiuk HJ, Tauskela JS, Morley P and Durkin JP: Selective coupling of mu-calpain activation with the NMDA receptor is independent of translocation and autolysis in primary cortical neurons. J Neurosci Res 54: 223-32, 1998.

15 Monyer H, Seeburg PH and Wisden W: Glutamate-operated channels: developmentally early and mature forms arise by alternative splicing. Neuron 6: 799-810, 1991.

16 Radin D, Purcell R and Lippa AS: Oncolytic properties of ampakines in vitro. Anticancer Res 38(1): 265-269. 2018.

17 Cao L, Liu X, Lin EJ, Wang C, Choi EY, Riban V, Lin B and During MJ: Environmental and genetic activation of a brainadipocyte BDNF/leptin axis causes cancer remission and inhibition. Cell 142(1): 52-64, 2010.

18 Liu X, McMurphy T, Xiao, R, Slater A, Huang W and Cao L: Hypothalamic gene transfer of BDNF inhibits breast cancer progression and metastasis in middle age obese mice. Mol Ther 22(7): 1275-1284, 2014.

19 Wu Y, Si R, Yang S, Xia S, He Z, Wang L, He Z, Wang Q and Tang H: Depression induces poor prognosis associates with the down-regulation brain derived neurotrophic factor of serum in advanced small cell lung cancer. Oncotarget 7(52): 8597585986, 2016.

20 Radin D and Patel P: BDNF: An oncogene or tumor suppressor? Anticancer Res 37: 3983-3990, 2017.
Received March 14, 2018

Revised April 23, 2018

Accepted April 30, 2018 